\title{
Surgeons' and occupational health departments' awareness of guidelines on post-exposure prophylaxis for staff exposed to HIV: telephone survey
}

\author{
S E Duff, C K M Wong, R E May
}

\begin{abstract}
Department of Surgery, Frenchay Hospital, Frenchay, Bristol BS16 1LE S E Duff, senior house officer C K M Wong, registrar R E May, consultant Correspondence to: Dr S E Duff, Department of Surgery, Winchester and Eastleigh Healthcare NHS Trust, Royal Hampshire County Hospital, Winchester SO22 5DG cduff68@aol.com
\end{abstract}

BMJ 1999;319:162-178

\section{Survey questions}

To both groups

- Are you aware of the guidelines from the Department of Health relating to post-exposure prophylaxis after occupational exposure to HIV?

- In your hospital, are there established guidelines for prophylactic action to be taken in the event of an accidental exposure to HIV?

- What do the guidelines recommend?

To occupational health departments only

- Do you give prophylaxis?

- What drugs does it consist of?

- When do you give post-exposure prophylaxis?

- For how long?

- How many healthcare workers have presented for consideration of post-exposure prophylaxis?

- How many have declined post-exposure prophylaxis? Why?

- How many have completed the course?

- How many have abandoned the course? Why?

- Is post-exposure prophylaxis available 24 hours a day? Where?

To surgeons only

- If you were accidentally exposed to HIV via a needlestick injury, do you know in what timeframe you should be taking prophylactic treatment? (a) 1 hour; (b) <24 hours; (c) 24-72 hours

- If you needed to get post-exposure prophylaxis out of hours, do you know where it is available in your hospital?

- Can you estimate the risk of seroconversion after a needlestick injury from an HIV positive patient?

Surgeons face the occupational risk of parenteral transmission of infection, in particular with HIV, percutaneous exposure to which carries an estimated risk of transmission of $0.3 \% .^{1-3}$ This risk may be reduced by antiretroviral prophylactic treatment. ${ }^{4}$ The UK Department of Health issued guidelines on post-exposure prophylaxis in June $1997 .{ }^{5}$ We assessed whether the guidelines had been implemented and whether surgeons were aware of them in the South and West health region.

\section{Methods and results}

We conducted a telephone survey of all the occupational health departments and on-duty general surgical and orthopaedic registrar grade surgical trainees in the South and West region. Separate sets of questions were used for occupational health departments and surgical trainees (box).

Eleven occupational health departments were surveyed in September 1998. All the departments were aware of the Department of Health's guidelines, and all had either implemented a local policy (10) or nearly completed implementation (1). All local policies offered triple therapy 24 hours a day for healthcare workers occupationally exposed to HIV. Nineteen healthcare workers presented for consideration of post-exposure prophylaxis, of whom 3 declined treatment, 7 stopped the course early because of low risk of HIV infection in the source, and 9 completed the course.

Twenty six surgeons (13 orthopaedic, 13 general surgery) were surveyed in 13 hospitals. Only 8 surgeons knew of the Department of Health's guidelines on post-exposure prophylaxis; 10 were aware that local guidelines existed, but only 2 of these were familiar with the local recommendations. The time within which prophylaxis should be obtained was correctly stated as one hour by 10 surgeons; 9 surgeons thought that post-exposure prophylaxis should be obtained within 24 hours, 3 (12\%) within 72 hours, and 4 did not know. Only 2 surgeons knew where to obtain post-exposure prophylaxis out of hours. No surgeons knew the correct estimated risk of seroconversion after a needlestick injury from an HIV positive patient. The incorrect responses were as low as $0.0025 \%$ and as high as $100 \%$, although 13 estimated a $<1 \%$ risk. The risk was estimated as $<0.3 \%$ by 5 surgeons, $0.3 \%$ to $<1 \%$ by $8,1-5 \%$ by $7,5-50 \%$ by 3 , and $50-100 \%$ by $2 ; 1$ surgeon did not hazard an estimate.

\section{Comment}

Most of the occupational health departments in the South and West region, in accordance with the Department of Health's guidelines, had local policies for risk assessment and counselling, 24 hour availability of post-exposure prophylaxis, and follow up protocols. However, despite national and local publicity, surgeons in the region were poorly informed about these guidelines, and their knowledge about percutaneous exposure to HIV was inadequate.

The risk of seroconversion to HIV after a percutaneous exposure may be increased if a large volume of infectious material is transferred or if the viral titre in the material is high. ${ }^{4}$ Antiretroviral treatment reduces the ability of the virus to replicate, allowing the intact immune system an opportunity to clear the virus and thereby reduce the risk of seroconversion. Treatment with zidovudine has been shown to reduce the risk of seroconversion by $80 \%{ }^{4}$ The use of triple antiretroviral therapy is thought to reduce further the risk of transmission and prevent an increase in zidovudine resistance.

It is important that information about percutaneous exposure to HIV and appropriate prophylactic treatment is circulated to surgeons effectively, especially as the recommended prophylaxis needs to be given within one hour of exposure. Further work is 
necessary to determine national trends in both the implementation of the Department of Health's guidelines and surgeons' awareness of them.

Contributors: SED wrote the questionnaire, collected and analysed the data, and wrote the paper. CKMW had the original idea for the study, advised on the questionnaire design, and helped to write the paper. REM advised on the questionnaire design and helped to write the paper. SED will act as guarantor for the paper.

Funding: None.

Competing interests: None declared.

1 Henderson DK, Fahey BJ, Willy M, Schmitt JM, Carey K, Koziol DE, et al. Risk for occupational transmission of human immunodeficiency virus type-1 (HIV-1) associated with clinical exposures. A prospective evaluation. Ann Intern Med 1990;113:740-6.

2 Tokars JI, Marcus R, Culver DH, Schable CA, McKibben PS, Bandea CI, et al. Surveillance of HIV infection and zidovudine use among health care workers after occupational exposure to HIV-infected blood. Ann Intern Med 1993;118:913-9.

3 Gerberding JL. Incidence and prevalence of human immunodeficiency virus, hepatitis $\mathrm{B}$ virus, hepatitis $\mathrm{C}$ virus, and cytomegalovirus among health care personnel at risk for blood exposure: final report from a longitudinal study. J Infect Dis 1994;170:1410-7.

4 Cardo DM, Culver DH, Ciesielski CA, Srivastava PU, Marcus R, Abitebou D. Case-control study of HIV seroconversion in health care workers after percutaneous exposure. N Engl J Med 1997;337:1485-90.

5 Department of Health. Guidelines on post-exposure prophylaxis for health care workers occupationally exposed to HIV London: DoH, 1997.

(Accepted 18 February 1999)

\section{Drug points}

\section{Possible interaction between clindamycin and cyclosporin}

Robert Thurnheer, Irène Laube, Rudolf Speich, Department of Internal Medicine, Division of Pulmonary Diseases, University Hospital Zurich, Zurich, Switzerland

We report two cases of a suspected interaction between clindamycin and cyclosporin.

Case 1 was in a 48 year old woman with $\alpha_{1}$-antitrypsin deficiency who had right sided single lung transplantation for end stage pulmonary emphysema. After B cell lymphoma affecting the transplanted lung was diagnosed, immunosuppression was reduced to a target concentration of cyclosporin of $100-150 \mu \mathrm{g} / \mathrm{l}$. Owing to bronchopulmonary infection with Staphylococcus aureus, treatment with oral clindamycin $600 \mathrm{mg}$ thrice daily was begun. Serum cyclosporin concentrations fell continuously so the daily dose was increased. After clindamycin treatment was stopped cyclosporin was reduced to the same dose as before antibiotic treatment (figure).

Case 2 was in a 39 year old woman with cystic fibrosis who developed bilateral pneumonia seven weeks after double lung transplantation. Bronchoalveolar washings showed $S$ aureus. Antibiotic treatment with oral clindamycin $600 \mathrm{mg}$ thrice daily was started. Over four weeks the dose of cyclosporin was continuously increased from 325 $\mathrm{mg}$ to $1100 \mathrm{mg}$ daily to maintain serum concentrations around $200 \mu \mathrm{g} / \mathrm{l}$. After clindamycin treatment was stopped the dose of cyclosporin was reduced to the same dose as before antibiotic treatment (figure).

Cyclosporin is extensively metabolised by the liver. Therefore, circulating cyclosporin concentrations may be influenced by drugs such as macrolide antibiotics which affect hepatic microsomal enzymes, particularly the cytochrome $P-450$ system. ${ }^{12}$ However, we did not find any reports of an effect of clindamycin on the $P-450$ pathway in literature databases or the manufacturer's medical event reporting system (Pharmacia Upjohn, personal communication). The oral bioavailability of cyclosporin depends on the intestinal P-glycoprotein (mdr1), which partly explains the large variation in daily dose of cyclosporin required among transplant recipients. ${ }^{3}$ Again, we found no information about the effects of clindamycin on intestinal carrier proteins.

A drug interaction is possible, and close monitoring of cyclosporin serum concentrations is warranted to avoid underdosing of immunosuppressed patients.

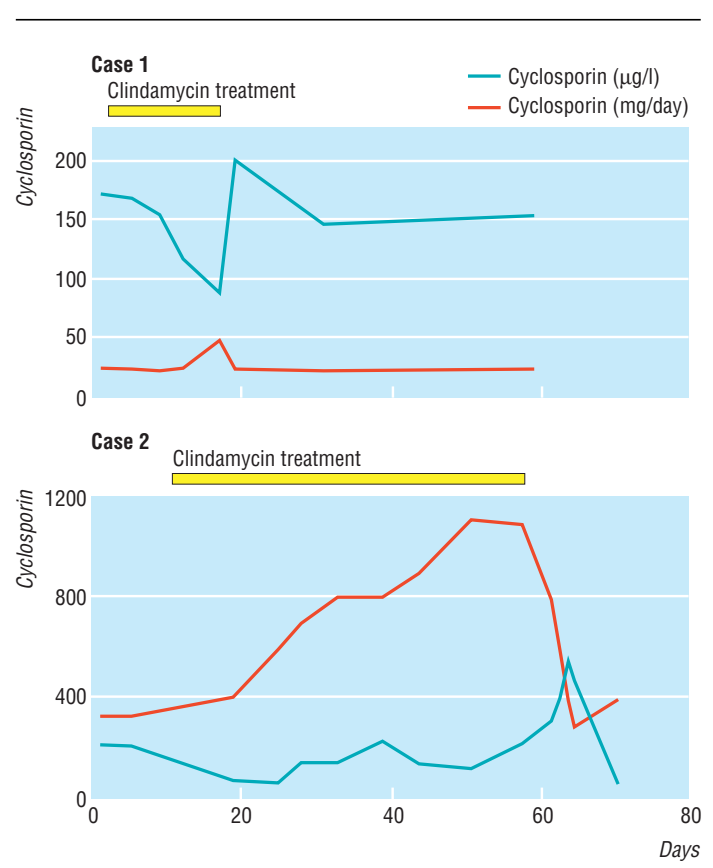

Cyclosporin concentrations and clindamycin treatment in cases 1 and 2

1 Spicer ST, Liddle C, Chapman JR, Barclay P, Nankivel BJ, Thomas P, et al. The mechanism of cyclosporine toxicity induced by clarithromycin. $\mathrm{BrJ}$ Clin Pharmacol 1997:43:194-6.

2 Ferrari SL, Goffin E, Mourad M, Wallemacq P, Squifflet JP, Pirson Y. The interaction between clarithromycin and cyclosporine in kidney transplant recipients. Transplantation 1994;58:725-7.

3 Lown KS, Mayo RR, Leichtman AB, Hsiao H, Turgeon DK, SchmiedlinRen P, et al. Role of intestinal P-glycoprotein (mdr1) in interpatient variation in the oral bioavailability of cyclosporine. Clin Pharmacol Ther 1997;62:248-60.

\section{Correction}

Reducing the risk of major elective surgery: randomised controlled trial of preoperative optimisation of oxygen delivery

An error occurred in this paper by Jonathan Wilson and colleagues (24 April, pp 1099-103). On p 1102 in the section headed "Oxygen delivery as a goal," the second sentence cited litres instead of millilitres. The sentence should have started "When oxygen delivery falls below $390 \mathrm{ml} / \mathrm{min} / \mathrm{m}^{2}$ $\left[\right.$ not $\left.\mathrm{l} / \mathrm{min} / \mathrm{m}^{2}\right]$...." 